\title{
Dependent Writers: A Writing Centre as a Bridge Between a Teacher-Centred Secondary School and Students' Independent Learning at a University
}

\author{
Barbara M. Gęsicka \\ Leeds Beckett University, Leeds, Poland
}

\begin{abstract}
This article discusses several aspects of starting a writing centre in a secondary school observed on a research group of students. First, it presents techniques involving students in independent development. As a response to writing being a solitary experience in the school curriculum and the teacher being a sole audience, the writing centre with its blog proposed forming a discourse community and shifting the students' dependence from the teacher to the audience consisting of peers. It provided the students with the environment (topics and peer feedback) that could engage them in exploring the social aspects of writing. The study was carried out to estimate the students' perception of the audience and the purpose of writing before and after two terms participation in the writing club activities. The article reports on the changes in students' attitudes after the intervention stage, such as improved confidence, time management, and use of feedback. It also advocates inviting other teachers to use and customize the writing club techniques, and to discuss their contexts of teaching and share ideas for possible adaptations and use.
\end{abstract}

Keywords: writing, independence, motivation

\section{Introduction}

In Poland, many tertiary education teachers voice their complaints about a drop in an average students' academic skills (Zalewski, 2011) and point to a gap between teacher's dependent learning at secondary schools and university education that requires much more independent approach from the student (Podsędkowski, 2013). Students who strongly depend on teachers for in-class guidance focused on their school leaving exams and realistic communication situations are of secondary importance to them (Chojnacka \& Salski, 2013). Starting tertiary education, they lack sufficient self-regulation strategies to engage in independent learning and to stream it in a desired direction and sustained motivation.

This article discusses several aspects of starting a writing centre in a secondary school. It concentrates on techniques involving students in independent development. As a response to writing, being a solitary experience in the school curriculum (Orr, 1998) and the teacher being a sole audience (Williams, 2005), the writing centre with its blog proposed forming a discourse community (Salski, 2011) and shifting the students' dependence from the teacher to the audience consisting of peers. It provides the students with the environment (topics and peer feedback) that could engage them in exploring the social aspects of writing (Mott, 2011). The study was carried out to estimate the students' perception of the audience and the purpose of writing before and

Barbara M. Gęsicka, Ph.D., School of Languages, Leeds Beckett University. 
after two terms participation in the writing club activities. This article reports on the changes in students' attitudes past the intervention stage.

\section{Teaching Writing in the Research Context}

Teaching in Poland remains heavily based on syllabuses designed by external bodies of the Ministry of Education clerks and assessment that can rarely-when time allows-be adapted for specific educational contexts, such as students' individual interests, previous experiences, or learning background (Reichelt et al., 2013). English is a compulsory subject taught as a general course with the use of one of the course books approved by the Ministry of Education, which introduce all language skills in activities designed particularly to prepare the students for their final exams. For reasons, such as lack of insight into the interests of a particular group of students and little knowledge of their level of language skills, the course books cannot personalize their content. It may mean that despite the fact that some common interests are included in the course book activities. Some students may still feel disappointed with the choice of topics.

Teaching is also very strongly exam-oriented. After three years of study, the students take a selection of final exams called Matura which, at the same time, is the university entrance exams. Matura consists of a range of obligatory subjects, such as Polish language, mathematics, and a foreign language at the basic level, plus from one to three chosen subjects at an advanced level.

\section{Current Practices and Attitudes-Teachers' Experience}

The writing component of the Matura in English has generally been considered to be the most difficult part, however, the reasons for the fact have been hard to specify among the students as well as the teachers in the research context. Both the students and the teachers attribute these reasons mainly to the shortage of the teaching time, unspecific assessment guidelines, or general lack of motivation in students and teachers. The preliminary field notes collected in the research context appear to confirm the assumption that writing is perceived as difficult. Some students complained they did not understand the instructions, so it was a waste of their time and they preferred writing in Polish, as they felt much more confident.

It is customary in many Polish classes to apply exam-like assessment to familiarize the learners with the system, which has no doubt that facilitating the process of revising towards the Matura. Nevertheless, it offers only a limited opportunity for improvement as the students delay submitting their tasks due to amount of work, and the teachers, who can hardly afford to spend extra time on assessing multiple drafts, are focused on final products. A common practice in Polish schools is to give the students writing tasks as homework that will be handed in and marked mainly for language mistakes, thus, making writing a solitary experience and a tedious task for those learners who find the process of writing difficulty.

\section{Feedback in the Research Context}

Drawing on the extensive teaching and examining experience, the author can say that in many Polish secondary schools teaching-writing concentrates on preparing students to take the Matura exam. As a result, the most pressure is put on producing a linguistically correct text. It is also the teacher who most often decides on the topic of a writing activity, and what content should be included in the text. With the focus on the product and writing being teacher-controlled, feedback in mainly concerned with linguistic aspects of the text. In the research context, giving feedback is teachers' responsibility. It comes in grades with occasional comments written on the text. The students are not accustomed to asking for clarifications, and they assume that the 
teachers always know best (field notes: "My friends are like me students, and they do not know my mistakes"). Drawing on the experience, such a traditional teacher-centred approach and fear of being ridiculed in class lead to a negative attitude to peer feedback.

It is also customary in Polish schools to ask learners to read their homework in class, and any mistakes are pointed out and corrected in public. The same applies to their texts. Consequently, learners may feel apprehensive, and in a competitive environment, they may feel understandably reluctant to discuss their work with peers (Salski, 2011). Thus, the students do not feel at ease when giving and receiving peer feedback. Research in the Polish context points out that peer feedback is rarely applied (Pawlak, 2016), and it is often related to grammar and vocabulary correctness (Lewandowska-Tomaszczyk, 2016).

\section{Literature Review}

\section{Writing as a Process and Social Interaction}

As far as the process of writing is concerned, it is a recursive activity. Being physically removed from the audience, the writer cannot exploit devices, such as gestures, movements, or voice available in speech. To achieve a coherent and expressive result, the writer needs to interact with the text, composing and planning, according to the purpose and the audience, which may involve drafting and revising for clarity and accuracy of meaning followed by editing for language accuracy (Hedge, 1992). To communicate the intended meaning, the writer must produce an outcome which is cohesive, i.e., linguistically consistent, as well as coherent, i.e., with consistent content. A writer needs skills to produce coherent and appropriate texts, to develop paragraphs coherently, and to use cohesive devices, which link parts of a text into logically related sequences. Cohesion signals relationships amongst ideas and makes the writer's intentions clear. Therefore, the writers may ask themselves a few questions that will specify the purpose of the text, the audience, and the register, all of which will help them make appropriate decisions about what vocabulary and structures to use to achieve a successful outcome. Cohesive devices include appropriate use of pronouns for referencing, conjunctions, lexical relationships, and so on. The most effective way to help students produce coherent and cohesive writing is offering practice at the text level, that is, encouraging the writing of whole texts (Hedge, 1992, p. 95).

Writing is also seen as a social act as it serves a purpose of establishing social positions and as such is an important factor in negotiating social relationships that do not result from obvious social criteria, like age or gender. When talking about language and society, Montgomery (1995, p. 140) claimed that persons achieved a social role and identity, not so much on the basis of publicly obvious and self-evident criteria, but more on the individual disposition and temperament. Thus, to obtain a desired social position, the writer needs to consider the rules and conventions to suit his or her purpose and retain a personal identity of the writer. A similar view of disposition and temperament was held by the expressivists (Elbow, 1998; Murray, 1985), who perceived writing as a creative process which required a positive and encouraging environment and minimal interference to encourage the writer's self-discovery of their own voices. However, in a social interaction, it is the communication between writers and readers that shapes the text. The audience for which the text is meant imposes on the writer certain requirements involving anticipating and assuming the reader's needs and expectations. This process influences the writer's individual approach to the text which in turn leads to shaping one's identity to achieve successful communication (Nystrand, Greene \& Weimelt., 1993). 


\section{Writing Pedagogy}

This section describes writing pedagogy in general and teaching writing skills in Polish secondary schools in particular.

During recent years, a number of theories have developed to support teaching writing. Many of them have been eagerly adopted by teachers and used to working in classrooms. The foci of these theories evolved around a selection of issues that constitute a range of aspects of writing, i.e., language structures, topics, content, genre, discourse functions, and writing processes among others. However, it cannot remain unnoticed that the theories, as well as the aspects, are not separate but rather complementary and it is up to the teacher as to which theory and methodology will be implemented in a particular situation, as the teacher needs to adapt to perspectives and limitations of a specific teaching context, namely, the learners' and teachers' preferences, the school curriculum, and external assessment. However, in the Polish education system, secondary school students write little, and although teachers have a wide array of methods and approaches at their disposal, both teachers and students see writing as a tedious chore, and the writing instruction is focused on meeting exam requirements rather than developing writing fluency (Reichelt et al., 2013)

\section{Personalizing Writing}

Many students of English as a foreign language (EFL) find it particularly troublesome when trying to convert their thoughts and ideas from first language (L1) to second language (L2) due to the fact that there is a significant challenge to choose appropriate vocabulary and grammar structures to convey the intended meaning, to follow appropriate genre conventions, to apply proper style and register, and achieve a coherent and cohesive text (Hedge, 1992). This negatively influences their curiosity in the task and diminishes natural satisfaction from achievement (Dörnyei, 1994). Hence, internal motivation is necessary to encourage the students to push through their limits. Such a breakthrough process may be fostered by a number of factors, i.e., topics of interest, those perceived as useful, or necessary at present and in future. Calkins (1986, p. 80) advocated making writing personal due to the fact that concern for language accuracy and convention destroyed involvement and interest of the writer who became detached and took few risks for the sake of correctness. Such an approach hampers writing engagement as learning spurts usually because of personal involvement, a willingness to take risks and opportunities to wrestle with more demanding challenges. Similarly, Tomlinson (2003, p. 162) proposed devising activities that involved the students in doing things that are connected to themselves, through incorporating their interests and knowledge. He advocated involving the students' experience of life and their attitudes, so that undertaking the writing task, the learner can feel at ease with the topic as well as the genre. The result of such an approach may be the desire to conquer such personal difficulties as lack of confidence or willingness to write.

\section{Procedures of the Research}

Basing on relevant literature, the field notes, and classroom observations, the author could raise the following issues that need detailed investigation. When writing tasks in the secondary school, the writer depends on the audience which is limited to the teacher and classmates. The main and often the sole purpose of a writing task is linguistic correctness, practising linguistic structures, grades, and revising for exams. This leads to making the context artificial and lacking authenticity.

The writer also needs to write required topics, use imposed genre and voice. Therefore, texts are devoid of personal approach and creativeness. Moreover, time limits of the lesson or teacher-set deadlines need to be 
observed. As a result of the above issues, the author decided to begin action research as a response to a strongly teacher-controlled process of writing at school.

The author started this action research as an opportunity to improve the teaching practices, and consequently, to better address the learners' needs. Therefore, the learners would benefit from any improvements resulting from the research (Hopkins, 2014). Thus, their unbiased opinions, either negative or positive, about writing in English could provide with the knowledge on how to increase their independence. This action research could be perceived as a collaborative teacher-students project where both parties could inform the changes implemented in the curriculum. Discussing the students' participation, the author invited the learners to take part in the research which could empower them to engage in their educational process.

The research question was formed: How to increase independence of secondary school students in developing their writing skills?

Having decided on the research methodology, the author designed the data collecting tools, i.e.:

1. A survey for the students (see Appendix I);

2. Semi-guided interviews with the students (see Appendix II).

The questionnaire provided a broad perspective of the situation, the author wanted to investigate. On the other hand, the interviews could provide a deep insight into a particular case. They could also supply with some additional advantages. In the semi-guided interviews, the respondents are more likely to discuss their opinions and disclose their feeling and values.

\section{Participants}

Table 1 below presents the data about the students participating in the study.

Table 1

Intervention Participants

\begin{tabular}{lllll}
\hline Studying for... & Level of English & Age & Participants & Time \\
\hline $\begin{array}{l}\text { Basic Matura-33 } \\
\text { Basic \& advanced Matura-9 }\end{array}$ & A2-B2 & $17-18$ & $\begin{array}{l}42 \\
\text { (female-18 and male-24) }\end{array}$ & $\begin{array}{l}\text { Term one and two } \\
2014 / 2015\end{array}$ \\
\hline
\end{tabular}

At the beginning of the research, all the participants completed the questionnaire (see Appendix I), which gave an insight into the students' attitudes to various aspects of writing and their degree of independence. The analysis of data collected by the pre-intervention questionnaire elicited the following issues important for this action research:

1. The participants could be separated in two groups of similar size. One group included the students who seemed to be quite confident and willing to develop their writing skills, and clearly perceived writing in English as necessary and useful in their future. The other group, however, included the students who expressed dislike for such activities and did not consider them particularly useful;

2. When considering the choice of topics, the students appreciated exam-oriented activities in course books, but were not satisfied with topics as far as their interests were concerned;

3. Some participants were willing to change the topics or create their own ones;

4. Supplementary resources were rarely used. Also, there was limited exchange of ideas among the students;

5. Although the students wanted to give writing activities their undivided attention, they approached it as a product completion rather than a process of recurring drafting and revising; 
6. Writing was considered as a waste of time, and the students did not seem to be very confident time managers when approaching writing tasks;

7. A considerable number of the participants were not confident about the content of their texts;

8. The participants felt generally accustomed to summative teacher feedback, both in an oral and written form, but felt apprehensive of peer feedback.

The questionnaire was followed by the semi-guided interviews. Their aims were to obtain a more detailed view of the students' approach to developing their writing skills and increasing their independence as writers. To triangulate the quantitative data collected by the Questionnaire I invited five participants for the interviews, all of which took place on the school premises at the time agreed by the participants. As the language level of the group was A2/B1, all participants decided to speak Polish, so all interviews were transcribed and translated into English.

The responses were grouped in the following categories:

1. Self-perception as a writer.

(1) Uncertain attitude towards future:

It is difficult to talk about the future.

If the teacher could control my progress, I would feel more motivated.

(2) Confident perception of future:

It is better when I get a ready topic, I think more, and I look for more words....

I liked an article the most because I could use my individual informal language, I could use my imagination and literary style.

The interviews showed that there was a group of the students who were uncertain about their future goals and needs and relied on the teacher to guide their development, which seemed to hamper their involvement and motivation. Only a few students demonstrated enough confidence that enabled them to make personal choices of tasks that would help them to improve their writing skills.

2. Topics.

(1) Positive perception of topics:

I like writing tasks related to life.

It depends which (course book) topics but if I must write about something, I do not know about, I must look it up on the internet. I cannot always write anything on a topic, so I have to support my knowledge with other resources and then I write.

I prefer topics related to my future because it is what interests me the most.

(2) No negative perceptions.

The students seemed to be satisfied with the choice of the topics in the course books. They also expressed preference for tasks and topics relevant to their future needs and likely to help them develop vocabulary and content knowledge.

3. Use of resources.

(1) Independent use of additional resources:

If (the topic) is interesting for me and I do not know much about it, I try to find information.

I may miss something and somebody will mention something. 
(2) Independent but non-cooperative attitude:

I prefer my ideas and I can check my knowledge, not my classmates' knowledge when I think about something else (to write).

(3) Poor use of resources:

I usually write basing on what I know, and I do not look for other ideas on the Internet.

Most of the students seemed to engage in looking for information on the content of the task to write an interesting text. The participants used additional resources, such as books, journals, or the Internet. Some of the students also engaged in peer cooperation to share their knowledge. There were only a small number of the participants who did not try to expand their content knowledge. Referring to the previous category-the topics, it seemed likely that the students' satisfaction with the topics led them to independent engagement in finding information to produce as interesting a text as possible.

4. Time management.

(1) Independent time management:

Teacher: Do you prefer to control the time yourself or leave it to the teacher?

Student: Myself.

Teacher: Do you feel you devoted it [the task] enough time?

Student: Rather enough, it is not a problem with me.

I always plan to start early enough to revise it and add something.

(2) Poor time management:

It is sometimes that I start earlier and I am sure I did it in the right time, analysed everything, and it was written well, but often you write a day before and it is written fast.

I always feel it was too little time.

Most of the participants seemed to perceive themselves as efficient time managers of the process of writing. However, there were a small number of them who noticed they still did not devote enough time for redrafting and revision of texts, and some who relied on the teacher to control the process of writing.

5. Feedback.

(1) Independent use of feedback:

It (multiple drafts) would motivate me.

I prefer additional individual explanations.

I often ask my father.

I think the teacher needs to explain everything that was wrong.

I have a file at home (with feedback).

(2) Attitudes towards peer feedback:

It depends because my sister when she criticises me I accept it but if my classmates then I do not know.

Teacher: Do you mind getting feedback from your classmates?

Student: No, only if they laugh at me.

The students expressed preference for the teacher feedback administered both in comments written on the text and verbally during individual teacher-student conferences. However, the students found it difficult to keep 
feedback for future reference, and to apply it in future tasks. They rarely returned to their texts to revise and redraft them and they expected feedback to concern mainly with correctness. Most of the interviewees were apprehensive of peer feedback unless it was positive or anonymous.

6. Teaching practices.

Teacher: Would you be motivated by designing topics?

Student: very much because I know much more about it and I do not have problems with thinking about what to write.

It is better when I get a ready topic.

Discussing the teaching practices, the students mentioned that course book activities were boring, and the class work hardly motivated them to engage in writing. They showed more positive attitudes towards such practices as brainstorming in class and were interested in the opportunities to design and adapt topics for writing and receiving feedback via e-mail. They would also appreciate sharing texts or parts of texts on a website.

7. Independence and confidence.

(1) Independent writers:

I can say that when I read about it, it is in English, so I know more words, I translate something, and then I remember it.

I adapt them [ideas] for my style and needs

Teacher: How do you know that the text is ready?

Student: When I run out of ideas, I mean I write a text, check if it is correct, and revise it and that is it.

(2) Teacher- dependent writers:

Teacher: What motivates you?

Student: I have not thought about it.

It is difficult to say but I think it [writing skills] is important.

Some students demonstrated moderate independence when searching for resources to develop the content matter of their texts and managing the process of writing. They engaged in peer cooperation, adapted ideas about writing for their own use, and referred to received feedback. On the other hand, there were a number of the students who had no clear vision of their L2 writing selves, were reluctant to cooperate with peers, rarely asked for additional feedback, and therefore, were not confident or independent when facing challenging writing activities. In addition, their engagement in the process of writing resulted mainly from the school requirements.

Summarising the results of the questionnaire and semi-guided interviews, the author could form some provisional conclusions. The results showed:

1. Reluctance to design new tasks - the students preferred teacher-designed ones;

2. Discouraging influence of failure;

3. Reluctance to publish;

4. Strong preference for teacher feedback;

5. Little autonomy-reliance on the teacher to control the process of writing;

6. Pressure to achieve-reluctance to write for pleasure;

7. Insufficient confidence about the content; 


\section{Insufficient critical interaction with texts; \\ 9. Negative perception of writing.}

\section{The Proposed Innovation}

\section{The Writing Club-Description of the Technique}

In response to the emerging difficulties listed above, and basing on relevant literature, the author designed the writing club where the students could practise several techniques and increase their independence as writers. The author hypothesised that innovative techniques with regard to teaching writing might help to encourage the students' independence and involvement (Dörnyei, 2005). The writing club the author suggested is intended not only to offer a wider variety of topics and forms for writing, but also to invite the students to suggest their own changes to topics and provide topics of interest, which could be published online for other students to share (Hidi \& Boscolo, 2007).

Hyland and Lo (2007) advocated taking more account of the learners' own socio-cultural context and focusing on topics related to personal and social concerns (p. 220). They also criticise very general topics as unrelated to students' lives. Hyland, Lo, and Tomlinson (2003) noted a link between independence and deep personal involvement with the topic. Also, some researchers (Strelau, 2000) pointed to development of imagination and creativeness in teenagers which was often expressed in the form of stories, poems, or diaries. They mentioned the presence of the audience facilitated independence and intensified engagement in tasks. Therefore, publishing texts could positively influence the students' motivation to write in English as well as open access to a much wider audience (Nystrand, Greene \& Weimelt., 1993).

Furthermore, the writing club offers an opportunity to post blogs as a means of expressing feelings and reactions related to writing tasks and publish some texts the students wrote in classes or as their autonomous writing. Kośmider (1997) in her research on Polish teenagers after 1989 noted that school did not promote individual ideas and solutions, and evoked fear resulting from challenges and overt teacher's control of students' class work and behaviour. Thus, the participants of this action research expressed fear of presenting their texts, dislike of peer feedback, and public assessment in class.

Eventually, the writing club aims to serve as a tool for promoting the students' control of the process of writing, i.e., the choice of the topic and resources, and sharing opinions, all of which might in turn result in a higher sense of self-confidence and self-regulation. In a strongly teacher-dominated context, which is the case in the school where action research was conducted, it is important to engage the students affectively not only through grades and exams, but by designing relevant and interesting tasks, delegating control of the writing process and promoting the sharing of opinions (Dörnyei, 2005). As a result, the author hoped that the students will be ready to accept control of their writing and develop a deeper sense of self-regulation which Pintrich (1991) described as the degree to which individuals were active participants of their own learning. Self-regulation involves cognitive, affective, motivational, and behavioural components that provide individuals with the capacity to adjust their actions and goals to achieve desired results (Zeidner, 2000, p. 751). Considering the participants' strong short term extrinsic motivation resulting from grades and exams, it can be assumed that difficulties might arise when the participants need to use their writing skills in new and complex academic or professional contexts. Therefore, this innovative technique of teaching writing needs to engage self-reflective thinking, planning, and independent approach (Wenden, 2002). 


\section{The Intervention-Collecting Data After Implementing the Innovative Techniques}

The intervention lasted for two terms, and 42 students participated in the writing club activities. Following the process of intervention, the students completed the same questionnaire as before the innovation. All the questionnaires that were returned and fully completed, and there were no missing lines and no purposefully frivolous answers, such as choosing answers to make a pattern of numbers "5-4-3-2-1".

The answers were coded from " $1=$ Strongly agree" to " $5=$ Strongly disagree" and " 0 value" was added to code the "Do not know" answer. The statistical significance of quantitative data was tested with the Wilcoxon-Mann-Whitney (WMW) test, which can be used with ordinal scale dependent variables when normal distribution or equal variances are not guaranteed. As this action research was a small-scale study, the author adopted a WMW test and decided to accept a more liberal $p$-value at 0.15 to estimate the significance, because of the short duration of each intervention stage. The author also considered mean values as more important indicators of occurring changes. The following section presents the analysis and interpretation of data collected by questionnaire after the implementation of the innovative techniques. Tables $2-5$ show the students' responses to the questionnaires before and after the intervention.

Table 2

Questionnaire Statements Referring to Topics Design

\begin{tabular}{llll}
\hline Sig. & After innovation & Before innovation & Questions \\
\hline $0.09^{*}$ & 2.45 & 2.3 & 1. I would like to suggest my topics to peers. \\
$0.07^{*}$ & 2.36 & 2.69 & 2. I know what I would like to write. \\
$0.03^{*}$ & 2.9 & 2.77 & 3. When I have a choice, I choose the easiest topic. \\
$0.08^{*}$ & 2.27 & 2.85 & 4. I like topics with challenging content. \\
$0.09^{*}$ & 1.75 & 2.85 & 5. When I can, I prepare my own topic. \\
\hline
\end{tabular}

Note. ${ }^{*}$ Marks significant changes with $p<0.15$.

The questionnaire elicited that the students were much more willing to prepare their own topics, undertake challenges, and choose different types of tasks. On the other hand, they expressed little satisfaction with topics designed by peers and did not feel motivated to choose tasks they found difficult.

Table 3

Questionnaire Statements Referring to Content of the Text

\begin{tabular}{llll}
\hline Sig. & After innovation & Before innovation & Questions \\
\hline $0.1^{*}$ & 2.83 & 2.92 & 6. I write my ideas to analyse and organise them. \\
$0.09^{*}$ & 2.25 & 2.69 & 7. I like brainstorming ideas in class, because I can use them for my writing. \\
$0.08^{*}$ & 2.33 & 2.3 & 8. I listen to my classmates' ideas to adapt them for my writing. \\
$0.1^{*}$ & 2.25 & 1.69 & 9. I look for ideas in additional resources. \\
$0.04^{*}$ & 2.9 & 2.08 & 10. I usually rely only on my knowledge of the topic. \\
$0.06^{*}$ & 3.0 & 3.15 & 11. I often read more on the topic before writing to get more ideas. \\
$0.06^{*}$ & 2.5 & 3.23 & 12. I usually feel confident about what to write. \\
$0.09^{*}$ & 2.0 & 2.3 & 13. Writing helps me to expand my knowledge on the topic. \\
\hline
\end{tabular}

Note. ${ }^{*}$ Marks significant changes with $p<0.15$.

The students demonstrated an increase in confidence about the content and much better interaction with the text to achieve a desired communicative outcome. They brainstormed and adapted ideas, and read much 
more on the topic before writing. However, there was a group of the students unwilling to use additional resources and perceiving writing as hardly conducive to expanding knowledge.

Table 4

Questionnaire Statements Referring to Time Management

\begin{tabular}{llll}
\hline Sig. & After innovation & Before innovation & Questions \\
\hline $0.14^{*}$ & 2.75 & 2.62 & 14. I usually write a draft, then revise, and redraft it. \\
$0.01^{*}$ & 3.81 & 3 & 15. Writing is a long activity that wastes my time. \\
0.31 & 2.08 & 2.0 & 16. I usually allow enough time to write and check the task. \\
$0.09^{*}$ & 2.09 & 2.3 & 17. I want the teacher to remind me to write the task. \\
$0.07^{*}$ & 3.25 & 3.62 & 18. I write additional tasks when I have some free time. \\
\hline
\end{tabular}

Note. ${ }^{*}$ Marks significant changes with $p<0.15$.

The students took better control of time and process of writing. The writing process was not delayed and enough time was allowed to interact with the text to achieve accuracy of meaning and language. The students also wrote more additional tasks. However, some participants still perceived writing as a waste of time and left writing a task until the deadline.

Table 5

Questionnaire Statements Referring to Feedback

\begin{tabular}{|c|c|c|c|}
\hline Sig. & After innovation & Before innovation & Questions \\
\hline $0.0^{*}$ & 1.75 & 1.54 & 19. I keep feedback for future reference. \\
\hline $0.0^{*}$ & 3.92 & 3.54 & $\begin{array}{l}\text { 20. I am afraid of getting my writing tasks back because I am afraid of } \\
\text { negative feedback. }\end{array}$ \\
\hline $0.08^{*}$ & 3.18 & 2.77 & 21. I often hand in extra work to get more feedback. \\
\hline $0.02^{*}$ & 3.33 & 2.3 & 22. I like to read my task to a friend to learn what she/he thinks about it. \\
\hline $0.08^{*}$ & 1.87 & 2.23 & 23. I like to get individual verbal explanations from the teacher. \\
\hline 0.19 & 1.5 & 1.77 & 24. I prefer teacher feedback to peer feedback. \\
\hline $0.01^{*}$ & 3.92 & 3.0 & 25. I do not feel confident during individual meetings with the teacher. \\
\hline $0.01^{*}$ & 3.81 & 3.07 & 26. I do not know how to use feedback to improve future writing. \\
\hline
\end{tabular}

Note. ${ }^{*}$ Marks significant changes with $p<0.15$.

The students felt more confident when discussing feedback with the teacher, expected individual explanations and better-employed feedback for future tasks. Conversely, they still preferred teacher feedback, avoided publishing on the club's website, and were reluctant to ask for additional or peer feedback.

\section{The Post Intervention Questionnaire-Data Interpretation}

The analysis of the data may lead to the following provisional assumptions:

1. The students' confidence about the content of a task increased which may lead to further independent development of writing skills;

2. Preference for self-designed topics may result in focusing on future goals. On the other hand, satisfaction with required topics may facilitate adapting for various contexts;

3. Increased independence in the use of additional resources shows more readiness to develop in various contexts;

4. Willingness to adapt ideas for writing and interact with the text implies increasing confidence and independence of the participants; 
5. Improved time management suggests more independent engagement in the process of writing, in the curriculum, and in revising for current and future assessment;

6. Engagement in additional tasks increased motivation to develop writing skills for proximal and distant goals;

7. Confident interaction with various audiences and motivation to undertake tasks despite previous failures may be attributed to a more positive attitude to feedback;

8. Better use of feedback may lead to further improvement of writing skills.

However, there remained some difficulties:

1. The participants were more focused on their shortcomings and did not appreciate their progress;

2. The data showed reluctance to accept peer feedback and avoiding publishing;

3. There was a strong perception of writing as a waste of time. The view seems to reappear when the participants perceived writing as not conducive to knowledge. Poor use of additional resources may have resulted from the above;

4. The data showed a vague vision of future goals and failure to think beyond the school context.

The author can suppose that the above difficulties resulted from limited time of implementing innovation and strongly rooted teacher-controlled assessment, increasing workload, and persisting extrinsic motivation.

\section{The Intervention-Summary of the Results}

Having analysed the results of both quantitative and qualitative data sets in relation to the research question, the author concluded that:

1. The students demonstrated better engagement in personalising tasks and preference for topics relevant for future needs and interests. They were willing to share ideas with peers, read more extensively on topics and showed more critical thinking related to the content of the task. The participants had more clarified perception of future needs, and therefore, were better motivated to expand knowledge and develop writing skills.

2. There was a shift from the product to process approach. The students demonstrated self-regulated involvement with the task, worked on texts independently and devoted more time to tasks. The participants showed more engagement in additional activities, and autonomy in designing tasks.

3. There was evidence of better attitude to feedback and confidence in individual contacts with the teacher implying more confidence in interaction with audience and the text. An independent approach to the process of writing including use of resources and time management implies an increased willingness to develop writing skills and implementing independent strategies of work. A positive attitude to and better use of feedback led to willingness to revise texts and engage in additional tasks, which implies better self-confidence.

4. The students demonstrated a more positive response to sharing ideas with peers and adapting them for their own purposes. They were satisfied with a selection of topics presented on the club's website and more confident about their knowledge and strategies to expand knowledge.

5. The participants increased their independence as a result of influences of significant others and future perspectives, and improved self-perception as writers. They declared a desire to write for pleasure and pointed to the influence of future needs and visions of themselves. 


\section{Summary of Research Reflections}

Having drawn on research evidence, the author can demonstrate that implemented innovative action successfully addressed the pressing issues articulated by the participants of this action research, i.e.:

1. Need to extend the range of types of activities and topics and to rethink their relevance to individual needs and interests;

2. Need for extra challenges;

3. Need for feedback administered to suit individual needs;

4. Need to relinquish teacher's control to encourage the students' independence;

5. Need to build on the students' independence gained outside the school context.

Referring to the remaining difficulties, the author can note that there is a further opportunity to develop the intervention and introduce necessary adaptations to innovative techniques of teaching writing in order to address areas of difficulties, such as implementation of peer feedback and willingness to publish. Drawing on positive results of implementing the innovation in the classes, the author can suggest that some actions should be undertaken to promote teachers' positive engagement in increasing students' independence in writing in English, to facilitate the process of teaching, and teacher-student cooperation.

During the process of intervention, the author noted considerable differences in the participants' responses, and therefore, consider it worthwhile to disseminate the findings and invite other teachers to use and customise the writing club techniques. First, the techniques could be presented in detail to groups of teachers, who could discuss their contexts of intervention and share ideas for possible adaptations and use. The writing club website could be presented to other teachers who could participate in its development. The teachers' section could be included to publish their comments and describe experience about teaching writing.

On balance, implementing the writing club activities as an optional opportunity for the students to complement their school learning seems to positively influence their independence as writers. It also helps to counteract students' excessive dependence on the teachers' control of the process of writing, and to minimise their insecurity related to feedback and audience responses.

\section{Conclusions}

Writing a blog to provide comments on the students' attitudes to writing positively influenced the students. They demonstrated more confidence about tasks, were more willing to take control of the process of writing, presented more positive response to feedback, and were willing to cooperate with peers as audience. The students had an opportunity to exchange opinions with the author via e-mail. This led to more confidence in personal communication with the teacher, better engagement in building independent strategies to develop writing skills and more positive attitude to feedback. Consequently, the participants are likely to develop self-regulation and autonomy when writing in English in future.

Designing writing activities as a way of relinquishing teacher's control-encouraged the students to focus on their needs and interests, engage, and expand knowledge, and in turn, engage in personalised tasks and submit more texts. The result showed increasing confidence as to topics, independent use of additional resources, more focus on the content and critical interaction with the text. The students also engaged in additional tasks and were more willing to adapt peers' ideas for their own purposes. They demonstrated satisfaction with topics presented on the writing club's website and were more involved in the curriculum 
activities. Consequently, the students may clearly perceive their needs and goals related to writing in English in future and feel motivated to work towards them.

Participating in a voluntary writing club to incorporate students' out of classroom writing enhanced confidence and autonomy of the students. They submitted more personalised tasks, allowed more time for revision and demonstrated less fear of public presentations of texts. This technique motivated the participants to concentrate on revising texts to publish a desired product, sustained engagement in tasks and led to improved self-perception and clearer vision of future L2 writing selves.

Concluding, despite remaining difficulties, such as average self-perception of the participants as writers, avoiding peer feedback, or publishing texts independently, the validation stage confirmed that innovative techniques implemented in the research context positively influenced the students' independence in writing in English.

\section{References}

Calkins, L. (1986). The art of teaching writing. Porthsmouth, N.H.: Heinemann.

Chojnacka, K., \& Salski, Ł. (2013). Authentic writing in the (foreign language) classroom-contradictory or doable? In J. Majer, \& Ł. Salski (Eds.), Foreign language opportunities in writing. Łódź: Łódź University Press.

Dörnyei, Z. (1994). Understanding L2 motivation: On with the challenge. The Modern Language Journal, 78(4).

Dörnyei, Z. (2005). The psychology of the language learner: Individual differences in second language acquisition. Mahwah, New Jersey: LEA Publishers.

Elbow, P. (1998). Writing with power: Techniques for mastering the writing process. Oxford: Oxford University Press.

Hedge, T. (1992). Writing. Oxford: Oxford University Press.

Hidi, S., \& Boscolo, P. (Eds.). (2007). Writing and motivation. Amsterdam: Elsevier.

Hopkins, D. (2014). A teacher's guide to classroom research. Maidenhead: Open University Press.

Kośmider, J. (1997). Relacje uczniów z nauczycielami (Teacher-student relationships). In B. Fotyga, \& A. Tyszkiewicz (Eds.), Dzisiejsza młodzież: Stereotypy i rzeczywistość po 1989 roku (Today's youth: Stereotypes and reality after 1989). Warszawa: Instytut Stosowanych Nauk Społecznych Uniwersytetu Warszawskiego.

Lewandowska-Tomaszczyk, B. (2016). Corrective feedback and writing skills in NS-NNS student collaborative translation tasks. EWCA Conference, Łódź, Poland.

Lo, J., \& Hyland, F. (2007). Enhancing students' engagement and motivation in writing: The case of primary students in Hong Kong. Journal of Second Language Writing, 16, 219-237.

Montgomery, M. (1995). An introduction to language and society. London: Routledge.

Mott, A. (2011). Turning classroom environments into centers of writing. In J. Majer, \& Ł. Salski (Eds.), Foreign language opportunities in writing. Łódź: Łódź University Press.

Murray, D. (1985). A writer teaches writing. Boston, M.A.: Houghton Mifflin.

Nystrand, M., Greene, S., \& Wiemelt, J. (1993). Where did composition studies come from? An intellectual history. Written communication, 19, 267-333.

Orr, M. (1998). Writing not boring. Modern English Teacher, 7(3).

Pawlak, M. (2016). Polish students' views on academic writing: Results of a questionnaire study. EWCA Conference, Łódź, Poland.

Pintrich, P. R. (1991). Manual for the use of the motivated strategies for learning questionnaire (MSLQ). Ann Arbor, M.I.: National Center for Research to Improve Postsecondary Teaching and Learning.

Podsędkowski, L., Kobierska, A., Sikora, M., Frącczak, Ł., Niewola, A., Zawierucha, M., \& Żak, P. (2013). Teaching in automatic control and robotics discipline in terms of changes in higher education system: Experiences and suggestions. Łódź: Politechnika Łódzka.

Reichelt, M., Salski, Ł., Andres, Lowczowski, E., Majchrzak, O., Molenda, M., ...Wiśniewska-Stecik, E. (2013). A table and two chairs: Starting a writing centre in Łódź, Poland. Journal of Second Language Writing, 22, 277-285.

Salski, Ł. (2011). The dynamic model of writing and its implications for the FL classroom. In J. Majer, \& Ł. Salski (Eds.), Foreign language opportunities in writing, Łódź: Łódź University Press. 
Strelau, J. (Ed.) (2000). Psychologia: Podręcznik akademicki (Psychology: Academic study book). Gdańsk: Gdańskie Wydawnictwo Psychologiczne.

Tomlinson, B. (Ed.). (2003). Developing materials for language teaching. London: Continuum.

Wenden, A. (2002). Learner development in language learning. Applied Linguistics, 23(1).

Williams, J. (2005). Teaching writing in second and foreign language classrooms. Boston: McGraw-Hill.

Zalewski, J. (2011). Beyond foreign language instruction: The need for literacy pedagogy. In J. Majer, \& Ł. Salski (Eds.), Foreign language opportunities in writing (pp. 5-19). Łódź: Łódź University Press.

Zeindner, M., Boekaerts, M., \& Pintrich, P. R. (2000). Self-regulation: Directions for future research. In M. Boekaerts, P. Pintrich, \& M. Zeidner (Eds.), Handbook of self-regulation (pp. 750-767). San Diego: Academic Press. 


\section{Appendix I}

The questionnaire statements:

1. I would like to suggest my topics to peers.

2. I know what I would like to write.

3. When I have a choice, I choose the easiest topic.

4. I like topics with challenging content.

5. When I can, I prepare my own topic.

6. I write my ideas to analyse and organise them.

7. I like brainstorming ideas in class because I can use them for my writing.

8. I listen to my classmates' ideas to adapt them for my writing.

9. I look for ideas in additional resources.

10. I usually rely only on my knowledge of the topic.

11. I often read more on the topic before writing to get more ideas.

12. I usually feel confident about what to write.

13. Writing helps me to expand my knowledge on the topic.

14. I usually write a draft, then revise, and redraft it.

15. Writing is a long activity that wastes my time.

16. I usually allow enough time to write and check the task.

17. I want the teacher to remind me to write the task.

18. I write additional tasks when I have some free time.

19. I keep feedback for future reference.

20. I am afraid of getting my writing tasks back because I am afraid of negative feedback.

21. I often hand in extra work to get more feedback.

22. I like to read my task to a friend to learn what she/he thinks about it.

23. I like to get individual verbal explanations from the teacher.

24. I prefer teacher feedback to peer feedback.

25. I do not feel confident during individual meetings with the teacher.

26. I do not know how to use feedback to improve future writing. 


\section{Appendix II}

\section{Semi-guided interviews questions:}

1. What types of topics for writing do you find interesting?

2. What types of topics for writing do you find useful for your studies/career?

3. What types of topics for writing do you find useful for future life?

4. Does the teacher/the course book provide such topics?

5 . What types of writing tasks are the most often given to you?

6. What genres/topics do you think you should write more often?

7. How often/how many of your classmates' ideas do you adapt for your writing?

8. Where do you look for ideas, if so?

9. If you are not confident about the topic or genre, do you look for information or avoid the topic? Why?

10. When you hand in your task, do you think you have given it enough time?

11. Do you prefer the teacher to control time and deadlines or not?

12. If not, do you feel confident as your own time manager?

13. Do you return to the task several times before handing it in? Why? Why not?

14. When do you know the task is good enough/finished?

15 . Why is or is not writing a waste of time?

16. When you get the teacher's feedback are you satisfied with comments and corrections? Do you find them helpful?

17. Do you keep previous tasks to be able to refer to comments?

18. Do you ask your peers for feedback on your writing? Why? Why not?

19. How do you use your teacher's feedback? Do you think you can improve your writing using feedback? 